\title{
Post-Traumatic Growth among Older People after the Forced Lockdown for the COVID-19 Pandemic
}

\author{
Montserrat Celdrán (D), Rodrigo Serrat (D) and Feliciano Villar (D) \\ Universitat de Barcelona (Spain)
}

\begin{abstract}
We explored post-traumatic growth (PTG) in older adults immediately after the forced lockdown in Spain during March to April, 2020, due to the COVID-19 pandemic. The study also tried to identify the variables that predict PTG, focusing on the experience of COVID, sociodemographic variables, and social resources. In total 1,009 people aged 55 years and older participated in the study and completed an online questionnaire comprising the following elements: The short form of the Post-traumatic Growth Inventory (PTGI-SF), sociodemographic and social resources questions, and their experiences of COVID-19 (if they had been infected themselves or if they had experienced the loss of someone close). Results showed that only a quarter of the participants experienced higher PTG after the forced lockdown, with only age and social resources being correlated with scores on the PTGI-SF. Looking at the strengths that older adults put into action to combat the pandemic and its social and health consequences could be an important consideration when planning future social policies for this and other pandemics.
\end{abstract}

Received 8 February 2021; Revised 14 July 2021; Accepted 19 July 2021

Keywords: coronavirus, older adults, post-traumatic growth

The SARS CoV-2 outbreak in 2019, which led to the COVID-19 pandemic, has had an impact on the daily lives of people of all ages that is unprecedented in the modern era. COVID-19 remains a worldwide emergency that is challenging all sectors of society (World Health Organization [WHO] 2020), including increased numbers of deaths and hospitalizations (Adhikari et al., 2020), adverse effects on the mental health of healthcare workers (Greenberg et al., 2020), and a greater burden of grief and bereavement (Mayland et al., 2020). Perhaps unsurprisingly, these consequences have attracted their own research interest.

The fact that older adults are more likely to experience serious complications (including death) from COVID19 have made this group the focus of public health decisions, political discussion, and media attention (Shahid et al., 2020). However, most studies have focused on the negative effects of the pandemic, including how severe disease affects older people (Mueller

Correspondence concerning this article should be addressed to Montserrat Celdrán. Universitat de Barcelona. Departament de Cognició, Desenvolupament i Psicologia de l'Educació.

E-mail: mceldran@ub.edu

Conflicts of Interest: None.

Funding Statement: Rodrigo Serrat is a Serra Húnter Programme tenure-track lecturer at the Universitat de Barcelona. et al., 2020), or the presence of ageism within society or when making medical decisions (Previtali et al., 2020). Less is known about the strengths and social or personal resources that older adults may use to cope.

Primarily, the present study aimed to fill the gap in our knowledge by exploring the strengths of older persons based on the concept of post-traumatic growth (PTG), as defined by Tedeschi and Calhoun (1996). As a secondary aim, we sought to identify the variables that predict this PTG in terms of the form of experience of COVID-19, the specific sociodemographic variables, and the social resources of older persons.

\section{Post-Traumatic Growth}

During our lifetimes, we each face events that deeply impact our health, emotional balance, social relationships, and life goals. Luhmann et al. (2020) have defined that important events (which they label as "major life events"; MLEs) are "events that are clearly timed, disrupt one's everyday routine, and are perceived as

How to cite this article:

Celdrán, M., Serrat, R., \& Villar, F. (2021). Post-traumatic growth among older people after the forced lockdown for the COVID-19 pandemic. The Spanish Journal of Psychology, 24. e43. Doi:10.1017/ SJP.2021.40 
personally significant and memorable by those who experience them" (p. 2).

Although many MLEs are reported as negative or highly stressful for the person, they can also positively affect psychological and social factors, leading to personal growth. This paper focus on the theory and process of PTG, which is defined as a "positive psychological change experienced as a result of the struggle with highly challenging life circumstances" (Tedeschi \& Calhoun, 2004, p. 1). This positive change could affect cognitive ideas or values, emotions, and behaviors (Tedeschi \& Calhoun, 1996). PTG has been studied especially in unexpected MLEs such as natural disasters (Tang, 2006), becoming a refugee (Chan et al., 2016), or facing a potentially fatal illnesses such cancer (Pérez-San-Gregorio, 2017) or HIV / AIDS (Sawyer et al., 2010). Research has shown that experiencing PTG predicts a good level of psychological and social adjustment after an MLE (Jayawickreme \& Blackie, 2016).

According to Tedeschi and Calhoun's (2004) model of PTG, experiencing an MLE poses several challenges. These include managing distressing emotions and questioning important beliefs and goals, both of which leave marks on a person's life narrative (Tedeschi \& Calhoun, 2004). Processes of rumination, such as deliberated rumination or meaning-making thoughts, are core to eliciting PTG (Calhoun et al., 2010). That is, it is not only the trauma itself that enables PTG but also the cognitive and emotional assessment and changes that people endorse about their life and future (Linley \& Joseph, 2004). Tedeschi and Calhoun's (2004) model provided the framework for building the PTGI-SF used in this study. It considers five areas of change: (a) Relating to others, (b) new possibilities, (c) personal strength, (d) spiritual change, and (e) appreciation of life (Cann et al., 2010). Variables have been studied that seem to influence the experience of PTG. Features of the event, such as time since it occurred and the type of event, as well as sociodemographic variables and social resources, have been stressed to be the most relevant (Wu et al., 2019).

\section{Facing COVID-19 and PTG}

Dealing with COVID-19 may be described as an undesirable life event for individuals, thanks to the low level of person control, low anticipation of the event, and lack of familiarity (Luhmann et al., 2020). These unique features mean that it cannot be compared accurately with previous literature on PTG or with other kinds of disruptive life events, such as wars (Chan et al., 2016) or natural disasters (Nalipay \& Mordeno, 2018). Although the social restrictions imposed due to COVID-19 have a clear time frame, as in the case of other major life events it is not known how much time is needed afterwards for PTG to occur. Following Wu et al. (2019), who stated that the best descriptions of PTG are those made closest to the event, this study was conducted immediately after the 49 days of forced lockdown in Spain. This time point was a landmark for many people - a moment of respite after the first wave of the pandemic. Moreover, the individual could have been exposed to the consequences of COVID-19 in at least one of three overlapping scenarios.

First, one can be infected by the disease. Research on this topic has focused on how to control the infection and how it impacts the person, either during the infection or in terms of negative long-term consequences (Ferrarese et al., 2020). Second, people may face the death of someone close because of COVID-19. The issues of bereavement and grief have been studied only by looking at the negative consequences of not being able to have a proper funeral or not being able to accompany the relative in the last moments of life (Burrell \& Selman, 2020). Third, most people had to deal with a forced lockdown to limit the transmission of infection. Again, only the negative effects of lockdown on family dynamics, especially those families that have children (Fontanesi et al., 2020), or on the increase in loneliness or psychological distress (Losada-Baltar et al., 2020) have been described.

The present research will explore differences in how PTG is experienced depending on exposure, taking into account participants that had direct experience of the virus (whether they were infected or they lost a close relative because of the virus) and those with indirect experience (i.e., only being involved in lockdown). This direct or indirect contact has been studied in other MLEs, such as the 9/11 attacks (Cann et al., 2010) and the Katrina and Rita hurricanes of 2005 (Stanko et al., 2015) in the US.

\section{Sociodemographic Variables Associated with PTG}

Few studies have explored the sociodemographic variables associated with PTG (Jayawickreme \& Blackie, 2016). Although sex, marital status, and age have each been associated with PTG, the results have been inconsistent (Helgeson et al., 2006). Women have been reported to express more PTG than men (Wu et al., 2019). This seems to be based on a tendency to use more positive appraisals as coping strategies to deal with traumatic or negative events. It may be that this cognitive strategy elicits PTG (Nowlan et al., 2015).

Widowhood and the process of bereavement have also been the focus of some studies, considering how this change can influence PTG. However, not all the bereaved adults experience PTG after a partner's death (Kim et at., 2011) and comparative studies has found no significant differences between widowed and nonwidowed adults (López et al., 2015). 
As for age, comparative studies have revealed less PTG among older people (Sim et al., 2015; Wu et al., 2019), although sample characteristics indicate that people older than 70 years are rarely included (Wu et al., 2019). Some studies suggest that the higher PTG scores among younger people could be explained by both the need to make life adjustments and the ease with which they can be made (Sawyer et al., 2010). However, other reviews have shown inconsistent associations between age and PTG (Linley \& Joseph, 2004; Stanton et al., 2006), with Davison et al. (2016) even explaining that older adults could experience more PTG due to the normal process of reminiscence and valuing life. This is consistent with the work of psychologist Erik Erikson (1963), who entitled this the final stage, integrity vs. despair, in his model of psychosocial development.

It is important that we study the experiences and challenges of older people during the COVID-19 pandemic given that this group has arguably suffered most from the disease and its consequences (Verity et al., 2020). Older age has been considered a risk factor for presenting health complications (or death) due to the virus (World Health Organization [WHO], 2021). Moreover, despite experiencing the same lockdown as younger people, this group has had to face greater fear of infection (Ishikawa, 2020), greater feelings of loneliness and social isolation (Tyrrell \& Williams, 2020), and ageism in terms of how authorities have dealt with the pandemic (Ehni \& Wahl, 2020). The greater vulnerability to COVID-19 and its negative impacts on physical, psychological, and social factors in older adults highlight the importance of studying PTG in this group. Given that such research may uncover protective factors for this population, this study focused on the positive impact of the COVID-19 pandemic on older adults.

\section{Social Resources and PTG}

The PTG model (Tedeschi \& Calhoun, 2004) stresses the importance of social resources and how networks could enable the person to disclose and talk about their feelings and worries regarding the trauma, potentially helping to elicit PTG. It is likely that the forced lockdown affected precisely those social resources, and that it potentially affected social isolation or feelings of loneliness (Brooke \& Jackson, 2020). Older adults who perceived higher social support during the forced lockdown did not experience an increase in loneliness, not even those who lived alone (Groarke et al., 2020; Luchetti et al., 2020). For example, many face-to-face befriending interventions adapted their programs to a phone-call format in order to reduce the risk of social isolation in older adults with limited technological skills (Kahlon et al., 2021). Given the importance of these social resources during lockdown, this study will explore their capacity for encouraging meaningful conversations with individuals' networks and for mitigating feelings of loneliness, above all in relation to PTG.

The COVID-19 pandemic is a unique MLE for most of us that has had many negative implications, but that may also have been associated with PTG. However, this has not been studied to date, so in this study, the aim was to assess PTG in older people in Spain during the forced lockdown between March and April 2020. It was hoped that this would reveal what COVID-19 experiences (personal infection, bereavement, and lockdown), sociodemographic variables, and social resources are associated with PTG.

\section{Method}

\section{Sample}

In total, 1,009 people aged 55 and older participated in the study (Table 1). All were senior students at the University of Experience of the University of Barcelona (Spain), their age range was 55-88 years, and all lived in Barcelona or its metropolitan area.

\section{Instrument}

The questionnaire administered to participants included three sections. The first section covered sociodemographic information, such as sex, number of children and grandchildren, marital status, and living arrangements. The second and third sections were then specific to COVID-19 and their experiences.

The second section comprised the short form version of the Post-traumatic Growth Inventory (PTGI-SF). Participants received instruction to assess the degree of change that they had experienced due to the COVID19 pandemic. Higher scores indicated that older adults perceive that they experienced more change due to the COVID-19. The PTGI-SF is a ten-item form that retains

Table 1. Description of the Sample

\begin{tabular}{lc}
\hline & Total \\
\cline { 2 - 2 } & $(N=1,009)$ \\
\hline Age $(M, S D)$ & $65.99(4.81)$ \\
Sex $(\%$ females) & 61.7 \\
Marital status $(\%$ married) & 62.1 \\
Living arrangement $(\%)$ & \\
$\quad$ With a partner & 51.2 \\
$\quad$ Living alone & 25 \\
With partner and children & 12.5 \\
$\quad$ Other & 11.3 \\
Number of children $(M, S D)$ & $1.69(.88)$ \\
Number of grandchildren $(M, S D)$ & $1.13(1.56)$ \\
\hline
\end{tabular}


the original five subscales of the PTGI (relating to others, new possibilities, personal strength, spiritual change, and appreciation of life) (Cann et al., 2010). Each item has six Likert-type answer categories, from 0 ("No change") to 5 ("a high degree of change"). Although its structure into five subscales ( 2 items per subscale), previous studies usually only used the full-scale scores (Vishnevsky et al., 2010). In this study, the Spanish translation by Cárdenas Castro et al. (2015) was used, for which the Cronbach's alpha was reported to be .83 and the five-subscale structure of the Spanish translation was deemed valid. In this study, Cronbach's alpha value reached .94.

The third section included a series of questions regarding the impact of COVID-19 and social resources. Two questions focused on Covid-19: If they had been infected by the virus (yes/no) and if someone close had died because of Covid-19 (yes/no). Regarding social resources during the lockdown, we asked about any changes in feelings of loneliness (increase, no change, or decrease) or the level of meaningful conversation (increase, no change, or decrease).

\section{Procedure}

The first author of this paper contacted the director of the University of the Third Age (University of Barcelona, Spain) and explained the objective of the study and the general procedure for data collection. After obtaining agreement to collaborate, a survey link was sent to all students. Qualtrics Surveys was used to create the questionnaire and monitor the survey distribution and responses. The online questionnaire included an introduction page in which information of the project and contact with the main researcher was given. Participants gave written informed consent in order to participate in the study and if only they gave their contest they were able to fill the questionnaire. The informed consent followed the same information the ethics committee formally approved.

There were 1,512 senior students studying one of fourteen degrees offered by the University in 20192020. The courses required twice weekly attendance at regular classes for senior students and at least one optional subject with undergraduate students. Due to the lockdown, however, all classes were suspended. The survey was conducted online for 17 days from $8^{\text {th }}$ May to $24^{\text {th }}$ May, immediately after the forced lockdown in Barcelona and its metropolitan area ended. During those 17 days, only walking and sports activities were allowed, and only at certain hours. No informal or formal meetings were allowed, and senior centers, shopping centers, bars, and restaurants were closed. Two reminder emails to complete the survey were sent to all students during the data collection period.
The final sample comprised 1,073 participants, giving a response rate of $70.97 \%$. However, 64 participants did not answer the PTGI-SF completely and were dropped from the analysis. Participants from all courses responded in high numbers, but those from gastronomy (82.1\%), psychology (76.1\%), and philosophy (71.6\%) courses responded in the highest proportions. This project received the ethical approval by The University of Barcelona's Bioethics Commission (CBUB).

\section{Data Analysis}

To analyze PTG differences because of impact of COVID-19, sociodemographic variables, and social resources, a series of $t$ test or correlations were performed, depending the nature of the variables studied. Thereafter, stepwise regression analysis was performed to explain the influence on overall PTG of the variables that had a significant impact in the correlation analyses. IBM SPSS Statistics version 25 was used to analyze the data.

\section{Results}

As shown in Table 2, PTGI-SF scores were diverse, with a mean of 17.54 (standard deviation: 12.54) and only $20.5 \%$ of the sample reaching $60 \%$ of the PTGI-SF score considered by Wu et al. (2019) to indicate a moderate-tohigh PTG. The highest subscale score was for "Appreciation of life" and the lowest was for "Spiritual change."

To analyze differences in PTG due to the impact of COVID-19 and according to sociodemographic variables and the availability of social resources, a series of $t$ tests or correlations were performed. Post-traumatic growth was significant associated with the experience of COVID-19, but only those who had been infected by it scored significantly higher on the PTGI-SF, $t(983)=$ $2.302, p=.022$, with no significant differences for participants who had experienced the death of a close relative because of COVID-19. Concerning the sociodemographic variables, only women, $t(995)=2,017, p=$ .044 , and younger participants $(r=-.098, p<.001)$ had significantly higher scores. Marital status, living

Table 2. Mean Scores of PTG

\begin{tabular}{lc}
\hline & $\begin{array}{c}\text { Scores of PTGI-SF } \\
M(S D)\end{array}$ \\
\hline $\begin{array}{l}\text { Total Post-Traumatic Growth (Range } \\
\text { 0-50) }\end{array}$ & $17.54(12.54)$ \\
Factor 1. Relating to others (0-10) & $3.94(2.92)$ \\
Factor 2. New possibilities (0-10) & $3.43(2.83)$ \\
Factor 3. Personal strength (0-10) & $3.70(3.01)$ \\
Factor 4. Spiritual change (0-10) & $1.90(2.35)$ \\
Factor 5. Appreciation of life (0-10) & $4.58(3.27)$ \\
\hline
\end{tabular}


Table 3. Variables Associated with Post-Traumatic Growth: Hierarchical Multiple Regression

\begin{tabular}{|c|c|c|c|}
\hline Variables & $\begin{array}{c}\text { Model } 1 \\
\beta(95 \% \text { CI })\end{array}$ & $\begin{array}{c}\text { Model } 2 \\
\beta(95 \% \text { CI })\end{array}$ & $\begin{array}{c}\text { Model } 3 \\
\beta(95 \% \text { CI })\end{array}$ \\
\hline \multicolumn{4}{|l|}{ Step 1} \\
\hline COVID-19 $(0=$ no $)$ & $7.79 *(.95,14.64)$ & $7.53^{*}(.72,14.34)$ & $5.53(-.99,12.05)$ \\
\hline \multicolumn{4}{|l|}{ Step 2} \\
\hline Age & - & $-.25^{* * *}-(-.42, .08)$ & $-.21^{*}(-.37,-.04)$ \\
\hline $\operatorname{Sex}(0=$ male $)$ & - & $1.52(-.13,3.16)$ & $.86(-.72,2.43)$ \\
\hline \multicolumn{4}{|l|}{ Step 3} \\
\hline \multicolumn{4}{|c|}{ Conversations $(0=$ No change $)$} \\
\hline Increase conversations & - & - & $6.87^{* * *}(5.23,8.50)$ \\
\hline Decrease conversations & - & - & $.71(-1.80,3.22)$ \\
\hline \multicolumn{4}{|l|}{ Loneliness ( $0=$ No change $)$} \\
\hline Increase loneliness & - & - & $3.75^{* * *}(1.79,5.71)$ \\
\hline Decrease loneliness & - & - & $4.60^{* * *}(2.03,7.17)$ \\
\hline$\Delta R^{2}$ & 0.005 & 0.014 & 0.097 \\
\hline$R^{2}$ total & $.005^{*}$ & $.019^{*}$ & $.116^{* * *}$ \\
\hline$N$ & 929 & 929 & 929 \\
\hline
\end{tabular}

Note. ${ }^{*} p<.05 .{ }^{* *} p<.01 .{ }^{* * *} p<.001$.

arrangements, number of children and grandchildren were not related to PTG. Finally, an increase in the number of meaningful conversations during lockdown, $F_{(2,1,000)}=49.219, p<.001$, and perceptions of loneliness (either an increase or a decrease; $F_{(2,982)}=15.123$, $p<.001)$ were associated with higher PTGI-SF scores.

All variables significantly associated with PTGI-SF scores were entered in a three-step hierarchical multiple regression analyses to explore their combined effects on PTG (Table 3). No multicollinearity was found between the different variables in any of the regression models, as VIF values were between 1 and 1.14. Durbin-Watson's value was 2.07, also within the recommended values for this statistic. In Step 1, direct exposure to COVID-19 was entered; in Step 2, sex and age were entered; and in Step 3, loneliness and level of meaningful conversations were entered. All three models were significant: Model $1, F_{(1,928)}=4.99, p<.05$, accounted for only $0.53 \%$ of the explained variance; Model $2, F_{(3,926)}=$ $5.99, p<.001$, increased the variance explained slightly to $1.9 \%$; and Model 3, $F_{(7,922)}=17.22, p<.001$, did increase the variance explained to $11.56 \%$. Overall, Model 3 offered the best goodness of fit, the following significant variables correlating with the PTGI-SF score: Younger age, increase in the number of meaningful conversations, those perceiving an increase in loneliness, and those perceiving a decrease in loneliness.

\section{Discussion}

The primary aim of this study was to describe PTG in older people in Spain after the forced lockdown due to COVID-19 of March-April 2020. However, it also analyzed if direct experience with the disease, sociodemographic variables, and social resources, such as changes in significant conversations or loneliness, were related to PTG.

Our results show the diversity of PTG in the studied population, but that only a quarter experienced higher PTG values, suggesting that lockdown itself was not the main determinant. Moreover, PTG was not higher among those directly exposed to COVID-19 either because they were infected or they experienced a close death. The nature of the event, its unpredictability, and the lack of previous experience may have affected how the process of PTG occurred. In that sense, an important requisite for PTG seems to be the time needed after the experience to start the necessary cognitive and emotional processes. Given that this pandemic is unique in the modern era, it is unknown how long it would take to see the long-term consequences of the pandemic could in different aspects of life, such as PTG, which was the focus in this research. In fact, many countries continue to struggle with the disease, and although there has been no more forced lockdowns in Spain, people remain unable to carry out daily activities as they did before the pandemic appeared. Therefore, some people may need more time to process the consequences of the pandemic, whether these are positive or negative.

The characteristics of the forced lockdown experienced in Spain may also explain the different focus on specific dimensions of the PTG, such as "Appreciation of life." As described as "Greater appreciation of life may develop as priorities shift dramatically and the "little things" in life are recognized for their value" (Riffle et al., 2020, p. 156), this recognition of these "little 
things" in person's lives may have been experienced precisely because of the lockdown and all the other major activities in their lives being removed.

Along with the direct experience of COVID-19 and its influence on PTG, we analyzed a set of sociodemographic and personal resources. This analysis showed that only age, the presence of significant conversations, and changes in loneliness were related to PTG. Youngolder adults experienced more PTG consistent with previous research supporting this correlation (Sim et al., 2015; Wu et al., 2019). However, those studies compared only younger and older adults, while the present research found the same negative tendency when focusing on older adults alone. The ease and necessity of making life adjustments in the young-older adults and the ease with which young-older adults resumed their routines and social activities could explain the age differences in PTG, as other studies have also suggested (Sawyer et al., 2010). For example, more than a year and half after the outbreak of the pandemic, many activities designed for older adults have still not reopened fully in Spain. Also, the older the person, the greater the exposure to the media message of vulnerability and the greater the fear of the disease. Therefore, even though social restrictions are being relaxed, these older adults still perceive the risk and do not regard the event as being over. These fears represent a major obstacle to the appearance of PTG. More studies are needed in the oldest old generation to understand more deeply the cognitive, affective, and social mechanisms that generate lower PTG in this population.

Other elements considered in this study could shed light on the diversity in PTG. One is the increase in amount of significant conversation. This variable was one of the core elements in Tedeschi and Calhoun's (2004) model of PTG. Having the opportunity to be involved in profound and significant conversations with important emotional or cognitive depth about the pandemic, fears of the disease, and how to face the future can trigger the necessary cognitive mechanisms to express PTG in a person.

Loneliness has been a direct consequence of the lockdown and the social changes to reduce the infection rates. Being prevented from social gatherings, visiting relatives or friends, or outdoor activities could directly affect the sense of loneliness and social isolation. This is especially relevant to Mediterranean countries such as Spain where those social activities are valuable to citizens (Fokkema et al., 2012). However, it was not the presence or absence of loneliness during lockdown, but the changes in this feeling, that affected PTG. It was the presence of a change in social relationships, not whether that change was positive or negative, that was most important. The change in equilibrium is what appears to be key to making people view their life or value their relationships differently, ultimately triggering feelings of PTG. On the one hand, the experience of loneliness has usually been portrayed negatively, but some studies have looked at solitude, seeking to focus on the positive impact of being or feeling alone (Lay et al., 2020; Ost Mor et al., 2020).

This solitude is described as the experience when someone needs to do an introspection task or take time to oneself to decide on goal or lifestyle changes (Lay et al., 2020; Ost Mor et al., 2020). This sense of solitude is precisely what the person needs to for PTG and could explain why some people who experienced increased loneliness still experienced high levels of PTG. On the other hand, those who experienced reduced loneliness during lockdown may have benefited from closer social relationships and experiencing more opportunities for social support and listening. In turn, these factors may have helped both groups to appreciate their lives and social relationships more, thereby contributing to PTG.

Some limitations of this study must be taken into account to understand the implications of those results and its replicability. First, the study took place just immediately after the 49 days of forced lockdown in Spain, so more time may be needed for PTG to develop. Further studies are therefore needed to follow this immediate scenario and clarify how older adults have adapted to new restrictions and new forms of social relationships. Secondly, the results of the multiple linear regression analysis indicate that a high percentage of the variance remains unexplained. Although the study included relevant variables that have been associated with PTG in previous studies, the unique experience of COVID-19 makes it important to explore other personal and social resources that might provide a better explanation of this personal growth after the pandemic. The use of only a few items to evaluate social resources and the impact of Covid is another limitation of this study. Further analyses with validated scales of loneliness or perceived support, as well as Covid-specific instruments (e.g., The Fear of Covid scale; Ahorsu et al., 2020) may help to explore in more detail how PTG appears after COVID-19. Finally, all participants were obtained by convenience sampling at the University of the Third Age, so our results cannot be extrapolated directly to all older adults. Students at this university tend to be better educated, in better health, and have a broader social network than older people in general (Villar, 2019). However, it is precisely this group that has probably seen the most drastic changes in their routines and lifestyles. This makes them an interesting population to follow the long-term consequences of social measures if they cannot continue as normal with life projects or other aspects of healthy aging (World Health Organization [WHO], 2015). 
In conclusion, this study has shed light on our understanding of the psychological effects of the COVID pandemic on the older population. The results highlight the importance of social relationships and the experience of loneliness as facilitators of PTG in the medium- or longterm. These data have practical implications for the design of interventions aimed at reducing social isolation and loneliness during periods in which physical distancing measures are in place. These interventions can benefit from the inclusion of elements that promote growth and learning among older adults (Williams et al., 2021). Indeed, many older adults attend the University of Experience in order to make friends, socialize and broaden their social network (Menéndez et al., 2018). Therefore, our results may also have practical implications for the administration of educational programs of this kind. These programs could allow participants to meet face-to-face in smaller groups or use their current online classes to create group dynamics outside the educational contexts that allow students to share their concerns regarding the pandemic. The results also show the importance of viewing older adults as agents of positive change, resilience, and plasticity. It is essential that we have a more balanced and diverse vision of how older adults have faced the COVID-19 pandemic, often successfully overcoming the focus on negative effects in their age group.

\section{References}

Adhikari, S. P., Meng, S., Wu, Y.-J., Mao, Y.-P., Ye, R.-X., Wang, Q.-Z., Sun, C., Sylvia, S., Rozelle, S., Raat, H., \& Zhou, H. (2020). Epidemiology, causes, clinical manifestation and diagnosis, prevention and control of coronavirus disease (COVID-19) during the early outbreak period: A scoping review. Infectious Diseases of Poverty, 9(1), Article 29. https: / / doi.org/10.1186/s40249-020-00646-X

Ahorsu, D. K., Lin, C. Y., Imani, V., Saffari, M., Griffiths, M. D., \& Pakpour, A. H. (2020). The fear of COVID-19 scale: Development and initial validation. International Journal of Mental Health and Addiction. https: / / doi.org/10.1007/ s11469-020-00270-8

Brooke, J., \& Jackson, D. (2020). Older people and COVID-19: Isolation, risk and ageism. Journal of Clinical Nursing, 29, 2044-2046. https: / / doi.org/10.1111/jocn.15274

Burrell, A., \& Selman, L. E. (2020). How do funeral practices impact bereaved relatives' mental health, grief and bereavement? A mixed methods review with implications for COVID-19. Advanced online publication. OMEGAJournal of Death and Dying. https: / / doi.org/10.1177/ 0030222820941296

Calhoun, L. G., Cann, A., \& Tedeschi, R. G. (2010). The posttraumatic growth model: Sociocultural considerations. In T. Weiss \& R. Berger (Eds.), Posttraumatic growth and culturally competent practice: Lessons learned from around the globe (p. 1-14). John Wiley \& Sons Inc. http:/ / doi.org/ 10.1002/9781118270028.ch1
Cann, A., Calhoun, L. G., Tedeschi, R. G., Taku, K., Vishnevsky, T., Triplett, K. N., \& Danhauer, S. C. (2010). A short form of the Posttraumatic Growth Inventory. Anxiety, Stress \& Coping, 23(2), 127-137. http:/ / doi.org/10.1080/ 10615800903094273

Cárdenas Castro, M., Barrientos Delgado, J., Ricci Alvarado, E., \& Páez Rovira, D. (2015). Spanish adaptation and validation of the posttraumatic growth inventory-short form. Violence and Victims, 30(5), 756-769. http:/ / doi.org/ 10.1891/0886-6708.VV-D-13-00165

Chan, K. J., Young, M. Y., \& Sharif, N. (2016). Well-being after trauma: A review of posttraumatic growth among refugees. Canadian Psychology/Psychologie Canadienne, 57(4), 291-299. https: / doi.org/10.1037/cap0000065

Davison, E. H., Kaiser, A. P., Spiro, A., III, Moye, J., King, L. A., \& King, D. W. (2016). From late-onset stress symptomatology to later-adulthood trauma reengagement in aging combat veterans: Taking a broader view. The Gerontologist, 56(1), 14-21. https:/ / doi.org/10.1093/geront/ gnv097

Ehni, H. J., \& Wahl, H. W. (2020). Six propositions against ageism in the COVID-19 pandemic. Journal of Aging $\mathcal{E}$ Social Policy, 32(4-5), 515-525. https:/ / doi.org/10.1080/ 08959420.2020 .1770032

Erikson, E. (1963). Childhood and society. Norton.

Ferrarese, C., Silani, V., Priori, A., Galimberti, S., Agostoni, E., Monaco, S., Padovani, A., \& Tedeschi, G. (2020). An Italian multicenter retrospective-prospective observational study on neurological manifestations of COVID-19 (NEUROCOVID). Neurological Sciences, 41, 1355-1359. https: / / doi.org/10.1007/s10072-020-04450-1

Fokkema, T., De Jong Gierveld, J., \& Dykstra, P. A. (2012). Cross-national differences in older adult loneliness. The Journal of Psychology, 146(1-2), 201-228. https:/ / doi.org/ 10.1080/00223980.2011.631612

Fontanesi, L., Marchetti, D., Mazza, C., Di Giandomenico, S., Roma, P., \& Verrocchio, M. C. (2020). The effect of the COVID-19 lockdown on parents: A call to adopt urgent measures. Psychological Trauma: Theory, Research, Practice, and Policy. 12(S1), S79-S81. http:/ / doi.org/10.1037/tra0000672

Groarke, J. M., Berry, E., Graham-Wisener, L., McKennaPlumley, P. E., McGlinchey, E., \& Armour, C. (2020). Loneliness in the UK during the COVID-19 pandemic: Cross-sectional results from the COVID-19 Psychological Wellbeing Study. PLOS ONE, 15(9), Article e0239698. https: / / doi.org/10.1371/journal.pone.0239698

\section{Greenberg, N., Docherty, M., Gnanapragasam, S., \&} Wessely, S. (2020). Managing mental health challenges faced by healthcare workers during covid-19 pandemic. BMJ, 368, Article m1211. https://doi.org/10.1136/bmj.m1211

Helgeson, V. S., Reynolds, K. A., \& Tomich, P. L. (2006). A meta-analytic review of benefit finding and growth. Journal of Consulting and Clinical Psychology, 74(5), 797-816. https:// doi.org/10.1037/0022-006X.74.5.797

Ishikawa, R. Z. (2020). I may never see the ocean again: Loss and grief among older adults during the COVID-19 pandemic. Psychological Trauma: Theory, Research, Practice, and Policy, 12(S1), S85-S86. http:/ / doi.org/10.1037/ tra0000695 
Jayawickreme, E., \& Blackie, L. E. (2016). Exploring the psychological benefits of hardship: A critical reassessment of posttraumatic growth. Springer.

Kahlon, M. K., Aksan, N., Aubrey, R., Clark, N., CowleyMorillo, M., Jacobs, E. A., Mundhenk, R., Sebastian, K. R., \& Tomlinson, S. (2021). Effect of layperson-delivered, empathy-focused program of telephone calls on loneliness, depression, and anxiety among adults during the COVID-19 pandemic: A randomized clinical trial. JAMA Psychiatry, 78 (6), 616-622. https://doi.org/10.1001/

jamapsychiatry.2021.0113

Kim, S. H., Kjervik, D., Belyea, M., \& Choi, E. S. (2011). Personal strength and finding meaning in conjugally bereaved older adults: A four-year prospective analysis. Death Studies, 35(3), 197-218. https: / / doi.org/10.1080/ 07481187.2010.518425

Lay, J. C., Pauly, T., Graf, P., Mahmood, A., \& Hoppmann, C. A. (2020). Choosing solitude: Age differences in situational and affective correlates of solitude-seeking in midlife and older adulthood. The Journals of Gerontology: Series B, 75(3), 483-493. https: / / doi.org/10.1093/geronb/ gby044

Linley, P. A., \& Joseph, S. (2004). Positive change following trauma and trauma: A review. Journal of Traumatic Stress, 17, 11-21. https:/ / doi.org/10.1023/B: JOTS.0000014671.27856.7e

López, J., Camilli, C., \& Noriega, C. (2015). Posttraumatic growth in widowed and non-widowed older adults: Religiosity and sense of coherence. Journal of Religion and Health, 54(5), 1612-1628. https: / / doi.org/10.1007/s10943014-9876-5

Losada-Baltar, A., Jiménez-Gonzalo, L., Gallego-Alberto, L., Pedroso-Chaparro, M. d. S., Fernandes-Pires, J., \& Márquez-González, M. (2020). "We're staying at home". Association of self-perceptions of aging, personal and family resources and loneliness with psychological distress during the lock-down period of COVID-19. The Journals of Gerontology: Series B, 76, e10-e16. https://doi.org/10.1093/ geronb/gbaa048

Luchetti, M., Lee, J. H., Aschwanden, D., Sesker, A., Strickhouser, J. E., Terracciano, A., \& Sutin, A. R. (2020). The trajectory of loneliness in response to COVID-19. American Psychologist, 75(7), 897-908. https:/ / doi.org/ 10.1037 / amp0000690

Luhmann, M., Fassbender, I., Alcock, M., \& Haehner, P. (2020). A dimensional taxonomy of perceived characteristics of major life events. Journal of Personality and Social Psychology. Advance online publication. https://doi.org/ $10.1037 /$ pspp0000291

Mayland, C. R., Harding, A. J., Preston, N., \& Payne, S. (2020). Supporting adults bereaved through COVID-19: A rapid review of the impact of previous pandemics on grief and bereavement. Journal of Pain and Symptom Management, 60(2), e33-e39. https: / / doi.org/10.1016/

j.jpainsymman.2020.05.012

Menéndez, S., Pérez-Padilla, J., \& Maya, J. (2018). Empirical research of university programs for older people in Europe: A systematic review. Educational Gerontology, 44(9), 595-607. https:/ / doi.org/10.1080/03601277.2018.1518459
Mueller, A. L., McNamara, M. S., \& Sinclair, D. A. (2020). Why does COVID-19 disproportionately affect older people? Aging, 12(10), 9959-9981. https: / / doi.org/ 10.18632/aging.103344

Nalipay, M. J. N., \& Mordeno, I. G. (2018). Positive metacognitions and meta-emotions as predictors of posttraumatic stress disorder and posttraumatic growth in survivors of a natural disaster. Journal of Loss and Trauma, 23 (5), 381-394. https://doi.org/10.1080/ 15325024.2017.1415734

Nowlan, J. S., Wuthrich, V. M., \& Rapee, R. M. (2015). Positive reappraisal in older adults: A systematic literature review. Aging \& Mental Health, 19(6), 475-484. https:/ / doi.org/ 10.1080/13607863.2014.954528

Ost Mor, S., Palgi, Y., \& Segel-Karpas, D. (2020). The definition and categories of positive solitude: Older and younger adults' perspectives on spending time by themselves. The International Journal of Aging and Human Development. Advance online publication. https:/ / doi.org/ $10.1177 / 0091415020957379$

Pérez-San-Gregorio, M. N., Martín-Rodríguez, A., BordaMas, M., Avargues-Navarro, M. L., Pérez-Bernal, J., Conrad, R., \& Gómez-Bravo, M. N. (2017). Post-traumatic growth and its relationship to quality of life up to 9 years after liver transplantation: A cross-sectional study in Spain. BMJ Open, 7(9), Article 017455. http:/ / doi.org/10.1136/ bmjopen-2017-017455

Previtali, F., Allen, L. D., \& Varlamova, M. (2020). Not only virus spread: The diffusion of ageism during the outbreak of Covid-19. Journal of Aging \& Social Policy, 32, 506-514. https:/ / doi.org/10.1080/08959420.2020.1772002

Riffle, O. M., Lewis, P. R., \& Tedeschi, R. G. (2020). Posttraumatic growth after disasters. In S. E. Schulenberg (Ed.), Positive psychological approaches to disaster (pp. 155-167). Springer. http:/ /doi.org/10.1007/978-3-030-32007-2_10

Sawyer, A., Ayers, S., \& Field, A. P. (2010). Posttraumatic growth and adjustment among individuals with cancer or HIV/AIDS: A meta-analysis. Clinical Psychology Review, 30 (4), 436-447. https:// doi.org/10.1016/j.cpr.2010.02.004 Shahid, Z., Kalayanamitra, R., McClafferty, B., Kepko, D., Ramgobin, D., Patel, R., Aggarwal, C. E., Vunnam, R., Sahu, N., Bhatt, D., Jones, K., Golamari, R. \& Jain, R. (2020). COVID-19 and older adults: What we know. Journal of the American Geriatrics Society, 68(5), 926-929. https: / / doi.org/ 10.1111/jgs.16472

Sim, B. Y., Lee, Y. W., Kim, H., \& Kim, S. H. (2015). Posttraumatic growth in stomach cancer survivors: Prevalence, correlates and relationship with health-related quality of life. European Journal of Oncology Nursing, 19(3), 230-236. https: / / doi.org/10.1016/j.ejon.2014.10.017

Stanko, K. E., Cherry, K. E., Ryker, K. S., Mughal, F., Marks, L. D., Brown, J. S., Gendusa, P. F., Sullivan, M. C., Bruner, J., Welsh, D. A., Su, L. J., \& Jazwinski, S. M. (2015). Looking for the silver lining: Benefit finding after Hurricanes Katrina and Rita in middle-aged, older, and oldest-old adults. Current Psychology, 34, 564-575. http:/ / doi.org/10.1007/ s12144-015-9366-2

Stanton, A. L., Bower, J. E., \& Low, C. A. (2006). Posttraumatic growth after cancer. In L. G. Calhoun \& R. G. Tedeschi (Eds.), 
Handbook of posttraumatic growth: Research and practice (pp. 138-175). Erlbaum.

Tang, C. S. K. (2006). Positive and negative postdisaster psychological adjustment among adult survivors of the Southeast Asian earthquake-tsunami. Journal of Psychosomatic Research, 61(5), 699-705. https: / / doi.org/ 10.1016/j.jpsychores.2006.07.014

Tedeschi, R. G., \& Calhoun, L. G. (1996). The Posttraumatic Growth Inventory: Measuring the positive legacy of trauma. Journal of Traumatic Stress, 9(3), 455-471. https: / / doi.org/ 10.1007/BF02103658

Tedeschi, R. G., \& Calhoun, L. G. (2004). Posttraumatic growth: Conceptual foundations and empirical evidence. Psychological Inquiry, 15(1), 1-18. https: / / doi.org/10.1207/ s15327965pli1501_01

Tyrrell, C. J., \& Williams, K. N. (2020). The paradox of social distancing: Implications for older adults in the context of COVID-19. Psychological Trauma: Theory, Research, Practice, and Policy, 12(S1), S214-S216. http: / / doi.org/10.1037/ tra0000845

Verity, R., Okell, L. C., Dorigatti, I., Winskill, P., Whittaker, C., Imai, N., Cuomo-Dannenburg, G., Thompson, H., Walker, P. G. T., Fu, H., Dighe, A., Griffin, J. T., Baguelin, M., Bhatia, S., Boonyasiri, A., Cori, A., Cucunubá, Z., FitzJohn, R., Gaythorpe, K., ... \& Ferguson, N. M. (2020). Estimates of the severity of coronavirus disease 2019: A model-based analysis. The Lancet Infectious Diseases, 20(6), 669-677. https: / / doi.org/10.1016/S1473-3099(20) 30243-7
Villar, F. (2019). From university extension classrooms to universities of experience: The University of the Third Age in Spain. In M. Formosa (Ed.), The university of the third age and active ageing: European and Asian-pacific perspectives: Vol. 23. International perspectives on aging (pp. 119-129). Springer. http://doi.org/10.1007/978-3-030-21515-6_10

Vishnevsky, T., Cann, A., Calhoun, L. G., Tedeschi, R. G., \& Demakis, G. J. (2010). Gender differences in self-reported posttraumatic growth: A meta-analysis. Psychology of Women Quarterly, 34(1), 110-120. https://doi.org/10.1111/j.14716402.2009.01546.x

Williams, C. Y. K., Townson, A. T., Kapur, M., Ferreira, A. F., Nunn, R., Galante, J., Phillips, V., Gentry, S., \& UsherSmith, J. A. (2021). Interventions to reduce social isolation and loneliness during COVID-19 physical distancing measures: A rapid systematic review. PLOS ONE, 16(2), Article e0247139. https:/ / doi.org/10.1371/ journal.pone.0247139

World Health Organization. (2015). World report on ageing and health. https:/ / www.who.int/ageing/events/worldreport-2015-launch/en/

World Health Organization. (2021). Coronavirus disease (COVID-19) pandemic. https://www.who.int/ emergencies/diseases/novel-coronavirus-2019

Wu, X., Kaminga, A. C., Dai, W., Deng, J., Wang, Z., Pan, X., \& Liu, A. (2019). The prevalence of moderate-to-high posttraumatic growth: A systematic review and metaanalysis. Journal of Affective Disorders, 243, 408-415. https: / / doi.org/10.1016/j.jad.2018.09.023 